\title{
Spatial Patterns and Driving Factors of Urban Residential Embedded Carbon Emissions: An Empirical Study in Kaifeng, China
}

\author{
Peng Yue', Peijun Rong2* \\ ${ }^{1}$ Yellow River Conservancy Technical Institute, Kaifeng, China \\ ${ }^{2}$ College of Tourism and Exhibition, Henan University of Economics and Law, Zhengzhou, China \\ Email:ypzzu@163.com, *rongpeijun@126.com
}

How to cite this paper: Yue, P. and Rong, P.J. (2019) Spatial Patterns and Driving Factors of Urban Residential Embedded Carbon Emissions: An Empirical Study in Kaifeng, China. Energy and Power Engineering, 11, 58-75.

https://doi.org/10.4236/epe.2019.112004

Received: February 1, 2019

Accepted: February 22, 2019

Published: February 25, 2019

Copyright $\odot 2019$ by author(s) and Scientific Research Publishing Inc. This work is licensed under the Creative Commons Attribution International License (CC BY 4.0).

http://creativecommons.org/licenses/by/4.0/

\begin{abstract}
With the continuous improvement in living standards and great changes in lifestyles, more attention is being paid to the embedded carbon emissions produced by human consumption. With large sample data and high-resolution remote sensing images, we explored the spatial differentiation and influencing factors of household embedded carbon emissions within the city fine scale using the EIO-LCA model, spatial autocorrelation analysis and standard deviation ellipse, quantile regression, etc. The results indicate that the spatial dependence is more obvious than the characteristics of spatial heterogeneity; the high-value area of household embedded carbon emissions gathers in new development zones in cities that are expanding rapidly, mainly with residents in large number of newly-built commercial housing families and the relative's courtyard of institutions. The factors of family characteristics, housing characteristics, lifestyles, and consumption concept have significant effects on the embedded carbon emissions of each person. The influencing intensity of most factors showed an increasing trend with increased carbon emissions. The study verified the impact of urban sprawl on residential carbon emissions and the applicability of the situated lifestyles theory in the construction of urban low-carbon communities in China.
\end{abstract}

\section{Keywords}

Embedded Carbon Emissions, Situated Lifestyles, Community Scale, Urban Residents, Kaifeng

\section{Introduction}

Mitigation and adaptation to climate change are an important topic for sustain- 
able development in the 21st century [1] [2] [3]. As an important component of greenhouse gases, $\mathrm{CO}_{2}$ emissions and their threat to human society continue to increase [4]. Residential carbon emissions are an important part of carbon emissions and consumption by residents is also the original drive behind industrial production [5]. For the question, "How is the responsibility for carbon emissions to be distributed?", the consumption side is considered more by academia than the productive side [6] [7]. Embedded carbon emissions refer to indirect emissions caused by consumption of non-energy goods and services, such as residential clothing, food, and shelter, which are implied in the full production. Supply and disposal life cycle are far greater than the direct carbon emissions generated by the direct consumption of fossil fuels by residents, and this conclusion has become the consensus [8].

With the rapid development of China's economy and the vigorous implementation of the policy of "expanding domestic demands", the role of household consumption of economic development has become more and more prominent. However, along with the continuous improvement in living standards and the increase in income, life consumption patterns have also experienced a major and gradual shift from "subsistence-oriented" to "quality-oriented". The demand for larger quantities and diversity of goods and services is also increasing. The transformation of residents' consumption patterns will not only contribute to economic and social problems, including industry, trade, and employment, but will also increase energy consumption and the generation of carbon emissions from the conduction effect of supply and demand [9]. Therefore, to the background of urban space optimization restructuring, large rise in living standards, and the sharp changes in residents' lifestyle, realizing regional low carbon development is a scientific problem to be solved [10] [11].

The promotion of housing marketization has resulted in differences in the living environment, lifestyles, and consumption patterns of the urban residents of communities and even building scales [12]. Academic concerns for residents' carbon emissions are also gradually from the perspective of the region to the family and community, that is, from a focus on the impact on economic development to focus on lifestyle, behavior patterns, and community space form on the residents' carbon emissions [13] [14]. China has continued to promote low-carbon development in the community and began to pilot low-carbon communities in 2014. In 2016, the National Development and Reform Commission and the Ministry of Housing and Urban-Rural Development issued the $A c$ tion Plan for Adaptation to Climate Change, which states: “To stick to 'different policies for different cities', step-by-step implementation, adopt reasonable measures, to carry out targeted adaptation actions." However, the carbon emission patterns of urban inner communities are still vague, the mechanism of the influence on residential carbon emissions is still unclear, and emission reduction indexes and models are not yet determined.

The construction of the accounting system for residential embedded carbon emissions of fine scales is the cornerstone and difficulty of the research. There 
are different methods and categories for the accounting of embedded carbon emissions. Among these methods, life cycle assessment (LCA) is a widely-used method that quantifies the environmental impacts on a production process [15]. Expansions of LCA include process-based (P-LCA) and input-output-based (IO-LCA).

The P-LCA method uses materials and energy data in every link in the production processes of commodities and analyzes each process in the product supply chain accordingly. The advantage of this method is the required level of refinement it can achieve, but analyzing every process in a supply chain is challenging and time-consuming, as system boundaries and categories become more and more extensive [16]. In contrast, the IO-LCA method can easily obtain the carbon emissions of the whole supply chain and eliminate cross-sectional errors but causes some uncertainty due to the degree of integration among the products and activities [17].

On the basis of the Leontief inverse matrix, Carnegie Mellon University Green Design Institute proposed the economic input-output life cycle assessment (EIO-LCA) model [18], which can analyze the environmental impact of a commodity from cradle to grave and the relationships of industries, which are widely used in current embedded carbon emission accounting [19] [20]. However, the application of this method is mainly based on the statistics of the city scale and the above [21] [22]. The data onto the community and family scales are difficult to obtain, so there is a lack of research.

There are many factors influencing residential carbon emissions, for which the mechanism is complex. At the macro level, the factors boil down to sizes of populations, economic levels, ideas and patterns of consumption, and the technical level, among the factors. The size of the population affects the level of consumption, the economic level impacts the power of consumption, ideas of consumption impact the quantity of carbon emissions, and consumption patterns affect the structure of carbon emissions, and commodity production technology influences the strength of the carbon emissions [23] [24] [25].

The micro-scale focuses more on the incomes of residents, sizes of families, ages of family members, numbers of home and car ownership, locations of residences, and housing areas and prices [26] [27]. Finnish scholars, Heinonen et al., have put forward their Situated Lifestyles Theory [28] [29], which summarize the influence mechanism from the perspectives of spatial behaviors. According to the theory, residential behaviors and ways of life are bound by the building environments and locations of residences. Residential morphology affects residence types, positions of distance, accessibility of goods and services, and the choice of social contact, pastime, which reflects on the aspect of behavior patterns, time distribution and the purchase decision, and then decided to residents' way of life. For the residential morphology affect type of residence, distance of home-work, accessibility of goods and services, the choice of social contact and way of pastime, and so on, and then decides the residential lifestyles including behavior patterns, time distribution and the purchase decision. The proposing of 
the theory was based on empirical research, but the theory remains to be further verified in residential areas or building scales. What are the differences in influencing strengths under different levels of carbon emissions? How is the spatial differentiation mechanism? These questions still need to be explored.

To answer these questions, we chose the city of Kaifeng as a study area where significant urban spatial changes and changes in residential lifestyle are occurring, where there are various types of urban residential areas, and where there is significant spatial differentiation in residential carbon emissions. The study is based on the theories of human-earth relationships and regional sustainable development, and follows the basic research framework of

"measure-pattern-mechanism". To reveal the spatial distribution of the carbon emissions of residents on a micro-scale and explore its influence mechanisms, we constructed a carbon emissions accounting system for residential households and used multidimensional statistical methods to analyze data from a large sample questionnaire survey in conjunction with high-resolution remote sensing imagery and national economic data. This study provides a theoretical basis and data support for policy-making for the construction of low-carbon communities.

\section{Study Area and Data}

\subsection{Study Area}

Kaifeng is located at the middle and lower reaches of the Yellow River in China (Figure 1). We selected the built-up areas of Kaifeng as the research area for the following reasons. First, Kaifeng is an important central economic zone and is typical of cities with rapid urban development. From 1985 to 2015, the urban population of Kaifeng increased from 62.91 million to 160.60 million, the rate of urbanization increased from $16.2 \%$ to $44.2 \%$, and the per capita disposable income of urban residents increased from 0.07 million yuan to 2.29 million yuan, which we can see from the statistical yearbook of Kaifeng. Second, Kaifeng has a long history, and different types of residential areas have arisen during its development and transformation. The policy of "Zheng-Kai integration" accelerated the construction of the city. There is a new development zone with high-rise buildings, as well as old urban areas of the "Eight Dynasties" with street, unit,

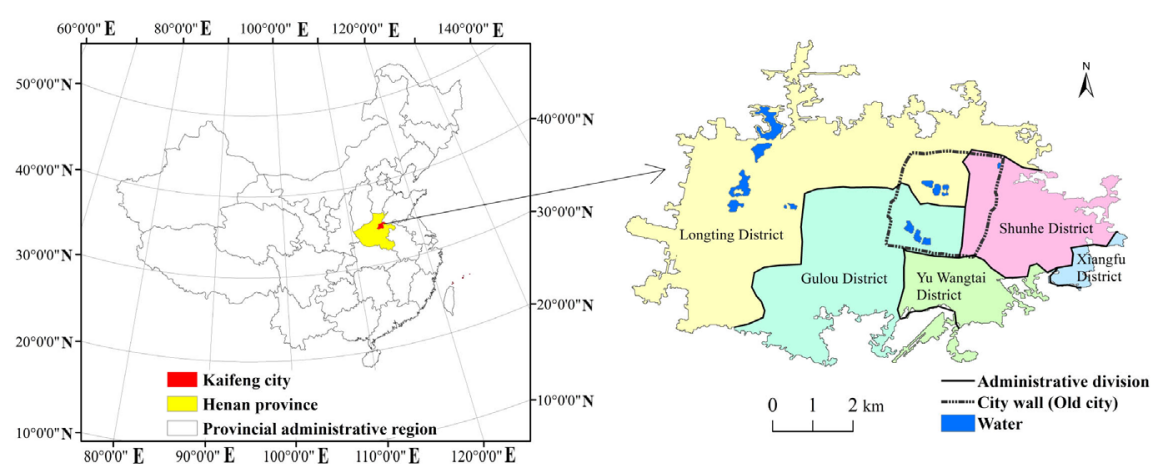

Figure 1. Study area. 
policy-based housing and commercial housing communities. The communities have different locations, spatial forms, and cultural characteristics. Third, Kaifeng belongs to the group of small and medium-sized Chinese cities. These cities are numerous and will play a major role in the construction of low-carbon cities in the future, but little research into the residential carbon emissions of such cities has yet been undertaken.

\subsection{Data Resources}

Data collected from questionnaire surveys are the key basic source of data for this study. Initially, a pre-survey was conducted with 200 questionnaires distributed randomly for a household survey. We revised and supplemented the questions after sorting and making a preliminary analysis of the questionnaire. A large-scale sample collection was then conducted in 2015 and 2016. We mainly adopted the methods of stratified random investigation. The proportions of the questionnaire were determined according to the proportion of the population distributed in the five administrative districts of the city some questionnaires were not used due to issues such as a lack of information and inconsistent or inaccurate positioning. Of the questionnaires, 5000 were distributed randomly at various public places, 4685 were returned, and 3895, involving 14,412 residents, were used for the analysis. The distribution of the sample points is shown in Figure 2. The contents of the questionnaire are related to the household demographic characteristics of residents, consumption features, and consumption cognition and preferences.

Socio-economic data includes: 1) Yearbook data, according to the calendar year, "Kaifeng Statistical Book" and "China Urban Statistical Yearbook", which include land capacity, population, urbanization rate, and car ownership, among other aspects, to establish an overview of the level of development in specific areas of Kaifeng; and 2) Input-Output Data utilized to calculate embedded carbon intensity for residents. The input-output data of Henan Province were only

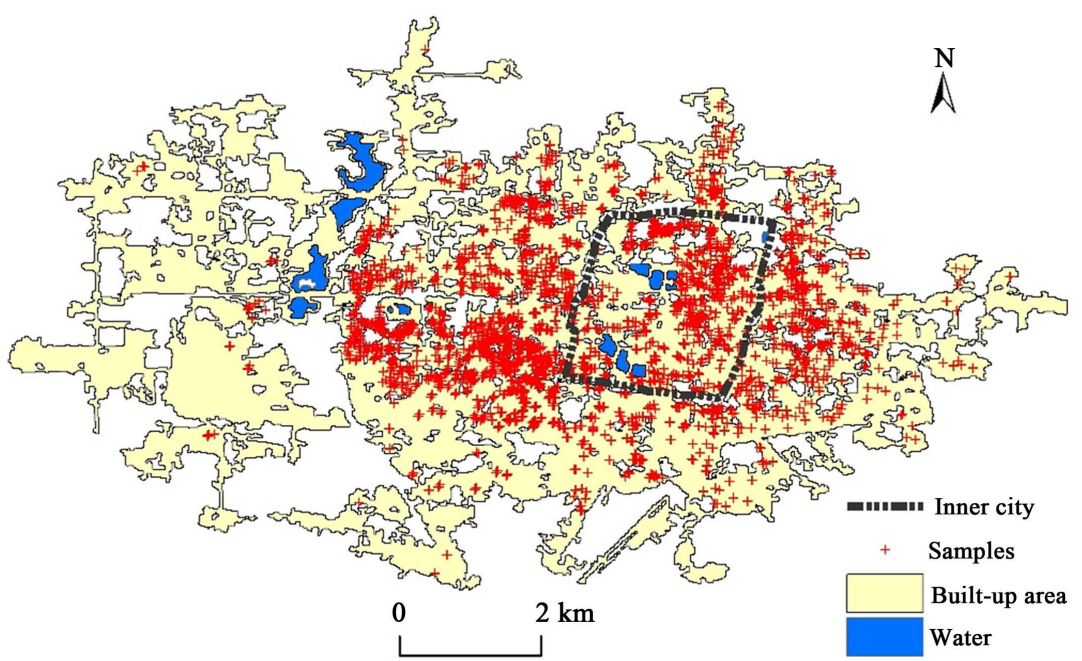

Figure 2. The spatial distribution of the samples. 
available until 2012 at the time of writing, as the data are compiled every five years. These data were extracted and merged with lifestyle data to establish a final consumer spending matrix. According to international practice, the carbon emission intensities of various industries in the province represent the microscale carbon emission intensity in the region (Kumar et al., 2016).

\section{Study Methods}

\subsection{Calculation Method of Embedded Carbon Emissions}

The EIO-LCA model, which can analyze the environmental impact of a product or service throughout the production chains from a lifecycle perspective, was used for the calculation of embedded carbon emissions [30], as given by Equation (1):

$$
E=R X=R(I-A)^{-1} F
$$

where $E$ is the specific energy consumption $\mathrm{CO}_{2}$ emission matrix for each sector; $R$ is the $k \times n$ order environmental pressure matrix; element $r_{i j}$ contained within $R$ represents the environmental burden $k$ (carbon emission); $A$ is the direct demand coefficient matrix; $(I-A)^{-1}$ is the Leontief inverse matrix; $X$ is the sum of all sector output vectors; and $\mathrm{F}$ is the final demand vector.

\subsection{Local Space Autocorrelation}

The global spatial autocorrelation method hypothesizes the spatial process is of stationarity, but in fact, this condition is difficult to satisfy. To overcome this limitation, we use the local space self-correlation method (LISA) to explore the autocorrelation characteristics of local spatial units in adjacent regions. The formula is:

$$
I_{i}=Z_{i} \sum_{i=1}^{n} W_{i j} Z_{j}
$$

where $Z_{i}$ and $Z_{j}$ are the normalized values of the observed values in the spatial units $i$ and $j$, respectively. $W_{i j}$ is the spatial weight.

\subsection{Standard Deviation Ellipse}

The Standard Deviation Ellipse (SDE) method can quantitatively explain the direction, spread, and centrality of the spatial distribution of geographical elements, and reveal the spatial distribution characteristics of the research objects more accurately. Specifically, the center represents the relative position of the elements in the two-dimensional spatial distribution, the azimuth indicates the direction of the main trend of the distribution, and the long axis reflects the dispersion degree of the geographical elements in the direction of the main trend.

The formula for the angle of rotation is:

$$
\tan \theta=\frac{\left(\sum_{i=1}^{n} \tilde{x}_{i}^{2}-\sum_{i=1}^{n} \tilde{y}_{j}^{2}\right)+\sqrt{\left(\sum_{i=1}^{n} \tilde{x}_{i}^{2}-\sum_{i=1}^{n} \tilde{y}_{i}^{2}\right)^{2}+4\left(\sum_{i=1}^{n} \tilde{x}_{i} \tilde{y}_{i}\right)^{2}}}{2 \sum_{i=1}^{n} \tilde{x}_{i} \tilde{y}_{i}}
$$


where $\tilde{x}_{i}$ and $\tilde{y}_{i}$ are the deviations of the coordinate of $x y$ to the mean center.

\subsection{Quantile Regression}

Least squares estimation can achieve the Best Linear Unbiased Estimation only when the former meet very strict assumptions (such as the random error term's obeying the same variance, no autocorrelation, normal distribution, no linear relations among different explanatory variables, etc.) In fact, the above conditions are extremely difficult to achieve, especially the social and economic problems with complex influencing mechanisms, and the robustness of the model becomes greatly reduced. In addition, the limitation of the conditions of the OLS average does not allow the response variable regression model to fully describe the conditions of different quantile functions, but only the average in the sense of dependence. What's more, the OLS regression model cannot fully describe the quantile functions of the different conditions of response variables but can only describe the dependence relationship of the sense of the mean value, so the problem cannot be explained completely or precisely. Therefore, Koenker and Bassett proposed the current Quantile Regression (QR) method based on the Median Regression method [31], which has some advantages in the study of residential carbon emissions, because it does not make any distribution assumptions and the estimated results are stable [27]. In essence, the model adjusts the position and direction of the quantile regression plane by selecting different values of the points on $0-1$, so as to estimate the dependent variables at different points with multiple covariates. The basic principle is:

$$
\sum w_{\tau}\left|y_{t}-\alpha\right|=-\sum_{i: y_{i}<\alpha}^{T}(1-\tau)\left(y_{t}-\alpha\right)+\sum_{i: y_{i} \geq \alpha}^{T} \tau\left(y_{t}-\alpha\right)
$$

where $\hat{y}_{(\tau) t}$ refers to the quantile regression estimator of $y_{t} w_{\tau}$ refers to the weight, and $\sum w_{\tau}\left|y_{t}-\alpha\right|$ refers to the sum of the absolute value of the weighted deviation for $y_{t}$ to any value $\alpha$. When $\alpha=\hat{y}_{(\tau) t},[\tau \in(0,1)]$, its value can be minimum.

\section{Results}

\subsection{Basic Characteristics of Residential Embedded Carbon Emissions in Kaifeng}

According to the input-output table of Henan Province and Equation (1), the embedded carbon emission intensity of 40 departments related to household consumption is calculated, as shown in Table 1.

When calculating the main living consumption category of residential embedded $\mathrm{CO}_{2}$ emission intensity, if a kind of consumption category corresponds to several industries, the weights of different industries are the proportion of its expenditure on the total expenditure of this category (Table 2).

According to EIO-LCA, the average household embedded carbon emissions in Kaifeng are $22.19 \mathrm{~kg} /$ day. The basic statistical characteristics of different types of embedded carbon emissions are shown in Figure 3. From higher to lower, the 


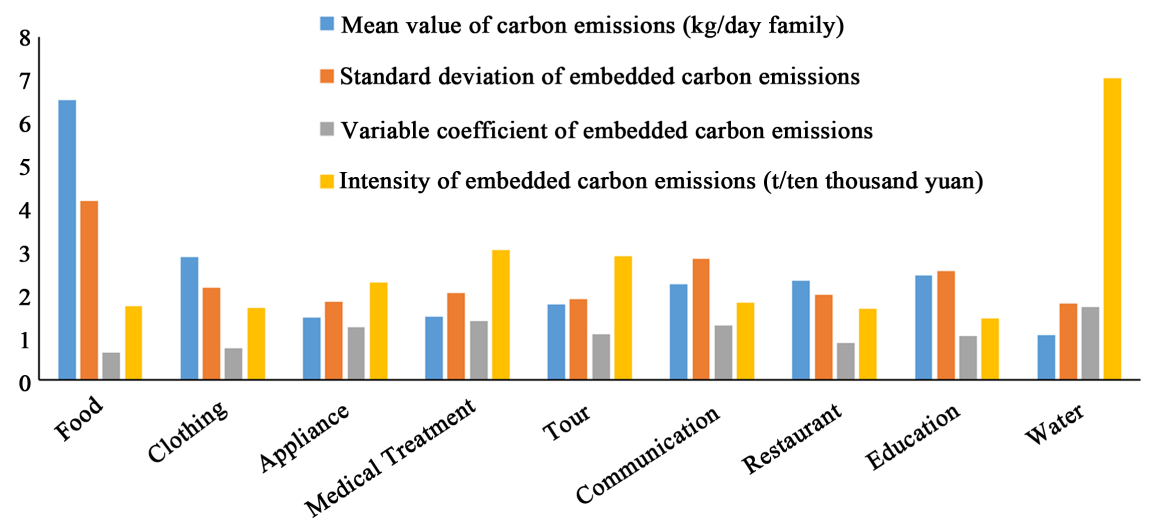

Figure 3. The basic statistical characteristics of embedded carbon emissions in Kaifeng.

Table 1. Embedded $\mathrm{CO}_{2}$ emission intensity in related industries.

\begin{tabular}{|c|c|c|c|}
\hline Department & $\begin{array}{l}\mathrm{CO}_{2} \text { emission intensity } \\
\text { ( } \mathrm{t} / \text { ten thousand yuan) }\end{array}$ & Department & $\begin{array}{l}\mathrm{CO}_{2} \text { emission intensity } \\
\text { ( } \mathrm{t} / \text { ten thousand yuan) }\end{array}$ \\
\hline $\begin{array}{l}\text { Agricultural and forestry animal } \\
\text { husbandry and fishery products }\end{array}$ & 1.2574 & Other manufactured products & 2.2814 \\
\hline Coal mining products & 13.9944 & Scrap waste & 4.2222 \\
\hline Oil and gas exploration products & 4.3262 & Electricity, thermal production, and supply & 16.8435 \\
\hline Metal mining products & 3.6089 & Gas production and supply & 6.9308 \\
\hline Non-metallic ore and other mining products & 2.5483 & Production and supply of water & 7.0528 \\
\hline Food and tobacco & 1.7200 & Building & 2.6830 \\
\hline Textiles & 1.7424 & $\begin{array}{l}\text { Transportation, warehousing, } \\
\text { and postal services }\end{array}$ & 4.1294 \\
\hline $\begin{array}{l}\text { Clothing, shoes, hats, and } \\
\text { leather down and its products }\end{array}$ & 1.6325 & Wholesale and retail & 0.9042 \\
\hline Wood processing and furniture & 1.7394 & Accommodation and catering & 1.6740 \\
\hline Papermaking and teaching sports articles & 2.7962 & $\begin{array}{l}\text { Information transmission, software, } \\
\text { and information technology services }\end{array}$ & 1.2380 \\
\hline $\begin{array}{l}\text { Petroleum, coking products, and nuc- } \\
\text { lear-fuel-processed products }\end{array}$ & 10.8082 & Financial & 1.4791 \\
\hline Chemical products & 4.2135 & Real estate & 0.5766 \\
\hline Non-metallic mineral products & 3.6932 & Leasing and business services. & 1.5293 \\
\hline Metal smelting and rolling processing & 4.7729 & Scientific research and technical services & 1.9375 \\
\hline Metal products & 3.6374 & $\begin{array}{l}\text { Water conservancy, environment, } \\
\text { and public facilities management }\end{array}$ & 1.3142 \\
\hline Special equipment & 2.8886 & $\begin{array}{l}\text { Resident services, } \\
\text { repairs and other services }\end{array}$ & 1.3271 \\
\hline Transport equipment & 2.9068 & Education & 1.0536 \\
\hline Electrical machinery and equipment & 2.6543 & Health and social work & 3.0443 \\
\hline $\begin{array}{l}\text { Communications, computers, } \\
\text { and other electronic equipment }\end{array}$ & 2.2277 & Culture, sports and entertainment & 1.4828 \\
\hline Instruments and meters & 2.2936 & $\begin{array}{l}\text { Public administration, social security, } \\
\text { and social organization }\end{array}$ & 1.6846 \\
\hline
\end{tabular}


Table 2. The industry corresponding to the main living consumption categories of residents and their embedded $\mathrm{CO}_{2}$ emission intensity.

\begin{tabular}{|c|c|c|}
\hline $\begin{array}{l}\text { Consumption } \\
\text { category }\end{array}$ & Corresponding industry (weight) & $\begin{array}{l}\mathrm{CO}_{2} \text { emission intensity } \\
\text { (t/ten thousand yuan) }\end{array}$ \\
\hline Food & Food manufacturing and tobacco processing industry (1) & 1.7200 \\
\hline Dress & Textile industry $(0.5)+$ Clothing, and leather down and its products $(0.5)$ & 1.6874 \\
\hline Home Appliances & $\begin{array}{l}\text { Electrical, mechanical and equipment manufacturing }(0.6) \\
+ \text { timber Processing and furniture }(0.4)\end{array}$ & 2.2883 \\
\hline Medical & Health, social security, and social welfare (1) & 3.0443 \\
\hline Tourism & Tourism (1) & 2.9017 \\
\hline Communications & $\begin{array}{l}\text { Communication equipment, computer, and other electronic equipment, } \\
\text { Manufacturing }(0.8)+\text { postal service, information transmission service }(0.2)\end{array}$ & 1.8163 \\
\hline Dining & Catering industry (1) & 1.6740 \\
\hline Schools & $\begin{array}{l}\text { Information transmission, computer services, } \\
\text { and software }(0.2)+\text { culture, sports, and entertainment }(0.8)\end{array}$ & 1.4338 \\
\hline Water & Production and supply of water (1) & 7.0528 \\
\hline
\end{tabular}

proportions of the different kinds of embedded carbon emissions are: food $29.43 \%$, clothing $12.99 \%$, education $11 \%$, dining out $10.51 \%$, communication $10.03 \%$, tourism $7.97 \%$, medical treatment $6.72 \%$, home appliances $6.62 \%$, and water $4.72 \%$. In addition, the intensities of the carbon emissions of water, medical treatments, and tourism are high. Meanwhile, the coefficients of variation of all kinds of embedded carbon emissions are very high, among them, the data dispersion degree of the carbon emissions from water, medical, communication, home appliance and child education are significant.

According to the spatial distribution patterns of embedded carbon emissions (Figure 4), the different levels of the carbon emission value are distributed in different regions, but there are significant differences among different regions. On the one hand, the density of the low value is high in the central and eastern areas, and the area east of the old city. On the other hand, the density of the high-value points gradually increases from the western region of the old city to the new development zone. Most samples around Zheng-Kai Road are high-value points. In addition, we found that the high and low values are mixed in the outer layers of the eastern, southern, and northern regions.

\subsection{The Spatial Differences of Residential Embedded Carbon Emissions}

From the results and the map of LISA regarding household embedded carbon emissions (Figure 5), we can see that $7.02 \%$ of the total sample points have significant spatial autocorrelation effects, of which the high concentration values $(\mathrm{HH})$ accounted for $31.93 \%$, high-low concentration values (HL) accounted for $21.08 \%$, low-high concentration values (LH) accounted for $10.84 \%$, and low concentration values (LL) accounted for $31.15 \%$. As can be seen from the 


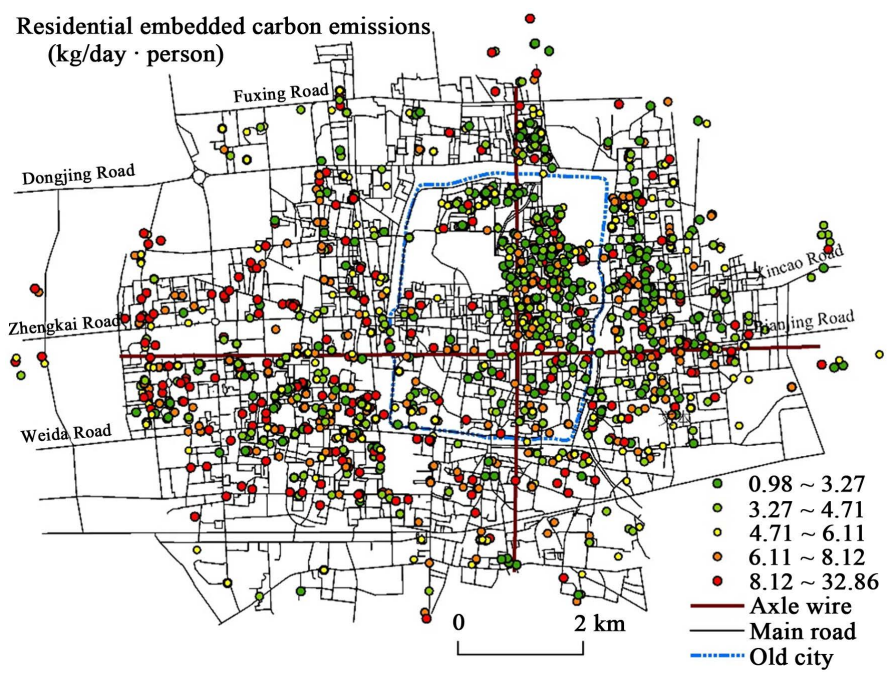

Figure 4. The spatial distribution pattern of residential embedded carbon emissions.
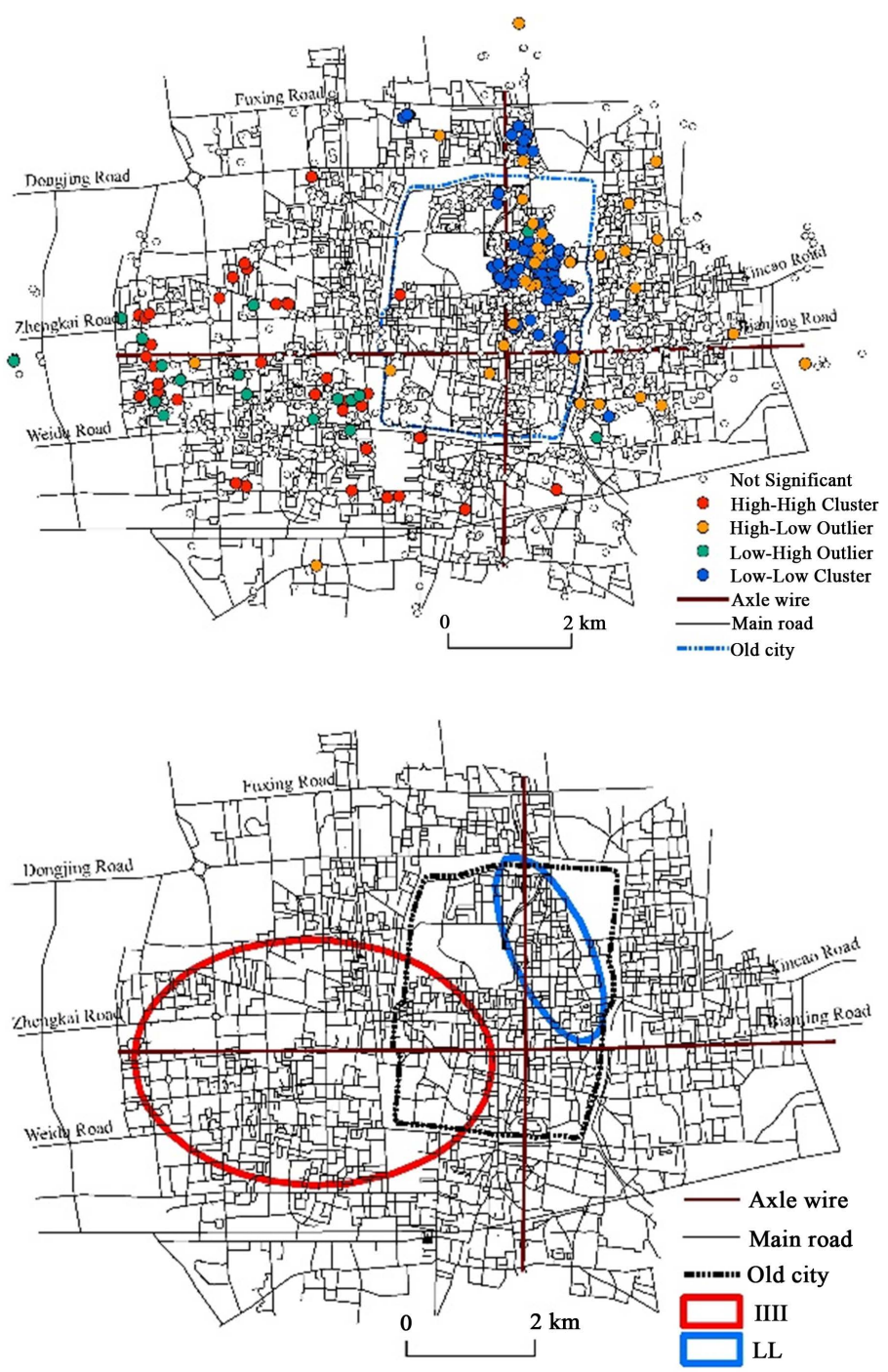

Figure 5. LISA cluster map and results of standard deviation ellipse for embedded carbon emissions distribution. 
proportion of $\mathrm{HH}$ and LL, the spatial dependence characteristics of family embedded carbon emissions are relatively obvious. On the one hand, the high-value agglomeration area of the embedded carbon emissions mainly exists in the western new development zone, mainly with a large number of new commercial housing community residents and family member courtyards of administrative departments and institutions, where most of the communities were built in recent years with high housing prices and perfect facilities. On the other hand, the low-value agglomeration areas are mainly in the northeastern area of the old city and the area east of the old town, mainly with the old commercial houses and the street communities. This shows that residential embedded carbon emissions have a high correlation with household income.

The standard deviation ellipse (SDE) method can further reflect the distribution center and trend of different agglomeration areas. The long axis represents the maximum diffusion direction, the short axis represents the minimum diffusion direction, and the area represents the discrete degree. The smaller the area, the greater is the concentration of the center. From the SDE result of household embedded carbon emissions (Figure 5), we can see that for the high-value agglomeration standard deviation ellipse, the area is $16.36 \mathrm{~km}^{2}$, the length of the $\mathrm{x}$-axis is $3.09 \mathrm{~km}$, the length of the $\mathrm{y}$-axis is $1.69 \mathrm{~km}$, and the angle of rotation of the $\mathrm{x}$-axis is $94.25^{\circ}$. For the low-value agglomeration standard deviation ellipse, the area is $2.85 \mathrm{~km}^{2}$, the length of the $\mathrm{x}$-axis is $1.42 \mathrm{~km}$, the length of the $\mathrm{y}$-axis is $0.64 \mathrm{~km}$, and the $\mathrm{x}$-axis angle of rotation is $154.33^{\circ}$. The $\mathrm{HH}$ ellipse center household per capita embedded carbon emissions are in the positive western direction and the dispersion degree is higher. The LL ellipse is located in the northeastern corner of the old city, and the agglomeration degree is high.

\subsection{Influencing Factors of Residential Embedded Carbon Emissions}

According to a related study, the influencing factors of embedded carbon emissions includes two main aspects: 1) the production system, which includes energy-saving technology, production efficiency, energy efficiency, etc.; 2) the consumption system, which includes income level, consumption habits and preferences, population sizes, etc. The product system determines the carbon emission coefficient (i.e., the carbon intensity of different consumer products), which is generally analyzed in the research at the macro scale according to the relevant statistical data, but the focus of this study is how micro-level improves the behavior of the residential preferences, consumption structure, and other relevant economic and social measures to reduce residential embedded carbon emissions, so we have chosen the influencing factors of the consumption system.

\subsubsection{The Comprehensive Influence Mechanism of Residential Embedded Carbon Emissions}

According to the relevant indexes mentioned in the literature review, the actual situation of local residential consumption, the family monthly income, building 
area, number of family members and the property of housing are used to characterize the family characteristics. The concept of low-carbon consumption is characterized by frugality, emphasis on low carbon consumption, timely suppression of family waste, the number of home-cooked meals, the number of trips per year, and the number of monthly beauty and healthcare products are used to characterize the family lifestyle. Consuming as little meat as possible, saving and reusing water, update cycle of furniture and household appliances, avoiding purchases of luxury goods, controlled consumption of mobile telephones and communications are used to represent behavioral preferences. Because of the large multi-items involved, we adopted the stepwise regression method to remove independent variables and chose embedded carbon emissions per capita as dependent variables to reflect the fairness of responsibility for the terminal emissions. The independent variables in the final model of residential embedded carbon emissions are shown in Table 3.

According to the results of the regression (Table 4), the whole equation passes the F significance test, showing that the regression equation has good statistical significance, as problems of complex social and economic fields with the big samples; the results have been able to reveal related issues [32]. Family characteristics, lifestyle, behavior habit, and the thought idea has significant influence on the embedded carbon emissions, among them, family income, and building area has a positive effect on embedded carbon emissions per capita, while number of family members, the housing property, number of cooking at home, consumption preference without luxury goods, emphasis of low carbon consumption and frugal purpose for saving money has a significant negative effect on embedded carbon emissions per capita.

Table 3. Descriptions of variables and statistical characteristics of embedded carbon emissions.

\begin{tabular}{|c|c|c|c|c|}
\hline Variable & Type & Instruction & Mean & $\begin{array}{l}\text { Standard } \\
\text { Deviation }\end{array}$ \\
\hline Building area & Continuous & Housing construction area size $\left(\mathrm{m}^{2}\right)$ & 120.94 & 55.30 \\
\hline $\begin{array}{c}\text { Number of } \\
\text { family members }\end{array}$ & Continuous & The number of members who live together in a house & 4.02 & 1.91 \\
\hline Housing property & Classification & Whether it is affordable housing: Yes $=1 ;$ No $=0$ & 0.17 & 0.38 \\
\hline Cook at home & Continuous & Average home cooking times per day & 2.29 & 0.75 \\
\hline $\begin{array}{l}\text { Frugal purpose } \\
\text { for saving money }\end{array}$ & Classification & $\begin{array}{l}\text { We are frugal in household management mainly to save money: } \\
\text { Very consistent }=5 \text {; Consistent }=4 \text {; General }=3 ; \\
\text { Not very consistent }=2 \text {; It does not fit at all }=1\end{array}$ & 3.67 & 1.33 \\
\hline $\begin{array}{l}\text { Emphasis of low } \\
\text { carbon consumption }\end{array}$ & Classification & $\begin{array}{l}\text { Family adults can focus on low-carbon consumption: Very consistent }=5 \text {; } \\
\text { Consistent }=4 \text {; General }=3 \text {; Not very consistent }=2 \text {; It does not fit at all }=1\end{array}$ & 4.30 & 0.87 \\
\hline $\begin{array}{l}\text { Consumption } \\
\text { without luxury }\end{array}$ & Classification & $\begin{array}{l}\text { Family adults do not pursue luxury goods: Very consistent }=5 \text {; } \\
\text { Consistent }=4 \text {; General }=3 \text {; Not very consistent }=2 \text {; It does not fit at all }=1\end{array}$ & 3.94 & 1.13 \\
\hline
\end{tabular}


Table 4. The gradual regression results for influencing factors of embedded carbon emissions per capita.

\begin{tabular}{cccc}
\hline Independent variables & Coefficient & Standard error & Significant \\
\hline (Constant) & 9.892 & 0.663 & 0.000 \\
Monthly household income & 0.529 & 0.075 & 0.000 \\
Number of family members & -0.372 & 0.048 & 0.000 \\
Housing property & -0.246 & 0.056 & 0.000 \\
Building area & 0.005 & 0.001 & 0.000 \\
Cook at home & -0.242 & 0.124 & 0.050 \\
Consumption without luxury & -0.213 & 0.105 & 0.042 \\
Emphasis of low carbon consumption & -0.426 & 0.082 & 0.000 \\
Frugality & -0.175 & 0.068 & 0.011 \\
\hline
\end{tabular}

Adjusted $\mathrm{R}^{2}=0.372 ; \mathrm{F}$ test 29.516 (sig. $=0.000$ ).

\subsubsection{The Differences in Influence Mechanisms under Different Embedded Carbon Emission Levels}

For a more detailed depiction of the dynamic mechanism of residential embedded carbon emissions, according to the theory of quantile regression, in combination with the results of stepwise regression analysis, we did the quantile regression estimate under $0.1,0.2,0.3, \cdots, 0.9$ quantile points. The estimated coefficients represent the marginal effect of the explanatory variable to the interpreted variable on the specific points.

From the quantile regression results (Figure 5), the influence strength of the monthly family income on embedded carbon emissions per capita has an increasing trend with the increase in carbon emissions. Most quantiles estimated coefficients are within the confidence interval of OLS estimates (Figure 5(a)).

The influence strength (absolute value of the negative influence) of the number of family members on carbon emissions has the trend of increasing first, then decreasing. The coefficient under 0.6 quantile is the turning point and the coefficient on 0.9 cannot pass the test of significance of $10 \%$, reflecting that the family size is not the main influencing factor for the families of the highest carbon emissions. In addition, the absolute value of its coefficient in the OLS estimates is less than in the quantile regression in most quantile points. Therefore, the OLS method has the possibility for estimating the role played by the number of family members on the carbon emissions (Figure 5(b)).

There are similar trends for the influence of family housing types, times of cooking at home, the extent of consumption without luxury, and emphasis of low carbon consumption on per capita carbon emissions. The absolute value of negative influence has an increasing trend. Most quantile estimated coefficients are within the confidence interval of the OLS estimate except the indicator of emphasis of low carbon consumption whose estimated values are in confidence interval of OLS estimates only at the $0.5,0.6,0.7$ quantile points and the coefficients of both sides of the median are symmetrical (Figure 5(c), Figures 5(e)-(g)). 
The influence strength of the family building area on embedded carbon emissions per capita also has an increasing trend with the increase in carbon emissions, but the estimated results do not pass the test of significance of $10 \%$ on the quantiles of $0.1-0.3$. That illustrates building area will have a significant impact to carbon emissions only for the group of high embedded carbon emissions, and the higher the level of carbon emissions, the greater the influencing strength of building area (Figure 6(d)).

There is a stable trend of influence of frugality on embedded carbon emissions per capita. The quantile estimated coefficients are generally within the confidence interval of OLS estimates. It explains that the influence of cognitive preference of low carbon on embedded carbon emissions were not significantly difference under different emission levels (Figure 6(h)).

\section{Conclusion and Discussions}

Using large sample questionnaire survey data, high-resolution remote sensing data, and the ESDA and SDE methods, we measured the spatial patterns of

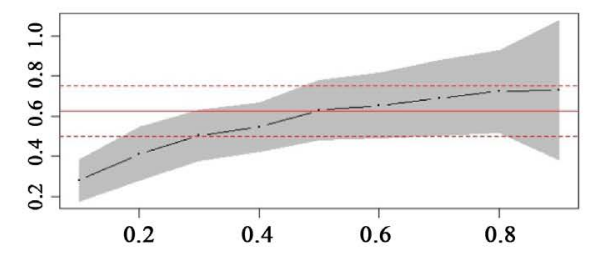

(a)

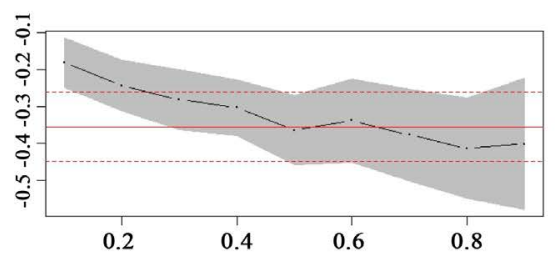

(c)

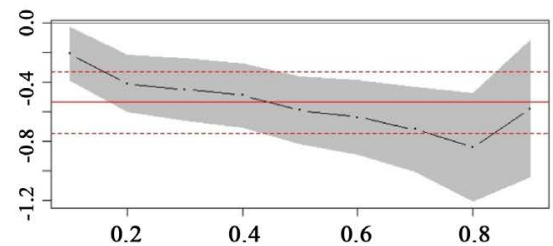

(e)

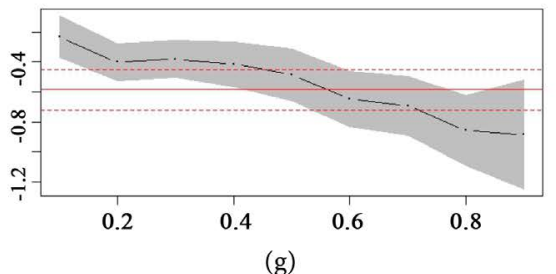

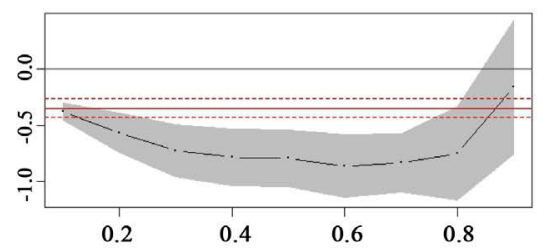

(b)

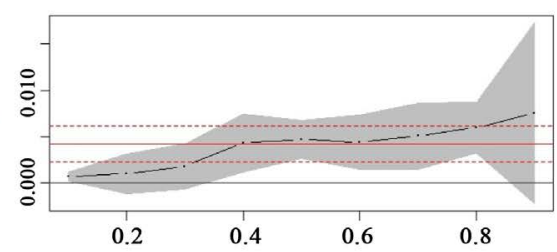

(d)

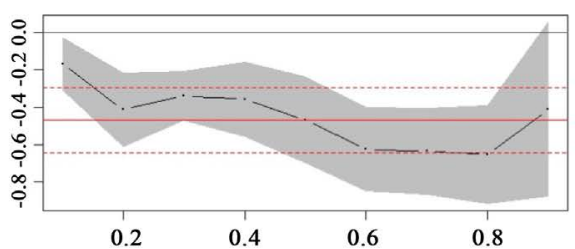

(f)

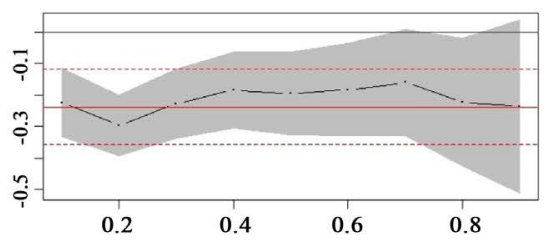

(h)

Figure 6. The quantile regression results for residential embedded carbon emissions. (a) Monthly household income; (b) Number of family members; (c) Housing property; (d) Building area; (e) Times of cooking at home; (f) Consumption without luxury; (g) Emphasis of low carbon consumption; (h) Frugal purpose for saving money. 
urban residential embedded carbon emissions on an internal fine scale in Kaifeng. Using the OLS and QR methods, we explored its comprehensive effect mechanism and the influencing differences at different levels of carbon emissions. The contribution of this research is that we calculated the indirect carbon emissions generated by residents' consumption in the fine scale through large sample survey and economic input-output life cycle assessment model, and clarified the spatial distribution pattern within the urban area and the reasons for its formation.

The spatial dependency characteristics of household embedded carbon emission are more obvious than the spatial heterogeneity characteristics. The cluster areas of high value of the embedded carbon emissions mainly exist in the urban newly built development zone with a large number of residents in new commercial housing communities and employees of administrative departments and institutions whose construction times are late, housing prices are high, and facilities are perfect. The low-value agglomeration area is mainly in the northeastern area and eastern areas of the old city, which are mostly the old commercial houses and street communities. At present, the area with the greatest development effort is the development zone in the western of the city where spreading quickly to the provincial capital Zhengzhou, and because of the advantages of geographic location, the house prices are relatively high, so residents there need to have certain economic basis, it also determines its various consumptions which may be higher than in other districts. Correspondingly, the outer layers of east, south, and north are in the developing state, so that the commercial housing of different levels, housing placement, and self-establish buildings in the rural-urban continuum are blended together, so the rule is not obvious.

We can see from a lot of high and low carbon emission mixed areas that the problem of residential embedded carbon emissions is complicated. Families with the same geographical locations, living environments, and spatial patterns may produce vastly different carbon emissions due to different family characteristics, lifestyles, and behavioral preferences. The regression result of influencing factors shows that the characteristics of family, lifestyle, behavior, and ideology all affect the embedded carbon emissions. The application of the quantile regression $(\mathrm{QR})$ method can more accurately reveal the different mechanisms of various influencing factors under different distribution functions and overcome the estimation error of the least square method on the mean level. The estimated results show that the influence strength of the remaining factors on embedded carbon emissions per ca-pita showed a trend of increase with the increase in carbon emissions, but the influencing strength of housing types and frugal purpose for saving money has the tendency of zigzag fluctuation. To a certain extent, the result emphasized the necessity of specific emissions reduction measures for high carbon emissions groups.

The conclusions are verified and supplemented for case application of situated lifestyle theory in Chinese cities from the perspective of residential carbon emissions, but there are limitations to the study. On the one hand, because of the fine 
scale of research, the data acquisition is difficult. This study only analyzes the spatial distribution of one time section. If the tracking survey of household consumption on a time dimension could be implemented or household energy and the public consumption statistic platform could be set up in the future, a richer conclusion will be obtained. On the other hand, further exploration of the influence mechanism of residential embedded carbon emissions is also the work to be carried out in future research.

Though we had calculated the indirect carbon emissions generated by residents' consumption in a fine scale, due to the difficulty in data acquisition, we only analyzed the spatial differentiation of one time section. In the future, if the tracking survey of the time dimension of household consumption is realized or the public platform of household energy and commodity consumption is effectively established, richer conclusions may be drawn. In addition, further exploration of the complex impact mechanism of resident embedded carbon emission is also the work to be carried out in the future research.

\section{Highlights}

Economic input-output life cycle assessment (EIO-LCA) model can be used for calculating the residential embedded carbon emissions.

There is obvious spatial dependence of residential embedded carbon emissions.

The high-emissions gather in new development zones that are expanding rapidly.

Specific emissions reduction measures for high emissions group are necessary.

\section{Acknowledgements}

This research was also supported by grants from Education Department of Henan Province (2019-ZZJH-149, 2019-ZZJH-093) and the China Postdoctoral Science Foundation (No. 2017M622333).

\section{Conflicts of Interest}

The authors declare no conflicts of interest regarding the publication of this paper.

\section{References}

[1] Pan, K., Li, Y., Zhu, H., et al. (2017) Spatial Configuration of Energy Consumption and Carbon Emissions of Shanghai, and Our Policy Suggestions. Sustainability, 9, 104. https://doi.org/10.3390/su9010104

[2] Liu, L.C., Cao, D. and Wei, Y.M. (2016) What Drives Inter Sectoral $\mathrm{CO}_{2}$, Emissions in China? Journal of Cleaner Production, 133, 1053-1061. https://doi.org/10.1016/j.jclepro.2016.05.126

[3] Qin, Y., Rong, P.J., Yang, Q.T., et al. (2014) Research Progress of Impact of Urbanization on Carbon Emissions. Progress in Geography, 33, 1526-1534.

[4] Li, J., Huang, X., Yang, H., et al. (2016) Situation and Determinants of Household Carbon Emissions in Northwest China. Habitat International, 51, 178-187. 
https://doi.org/10.1016/j.habitatint.2015.10.024

[5] Lu, H. and Liu, G. (2014) Spatial Effects of Carbon Dioxide Emissions from Residential Energy Consumption, A County-Level Study Using Enhanced Nocturnal Lighting. Applied Energy, 131, 297-306. https://doi.org/10.1016/j.apenergy.2014.06.036

[6] Das, A. and Paul, S.K. (2014) $\mathrm{CO}_{2}$ Emissions from Household Consumption in India between 1993-94 and 2006-07: A Decomposition Analysis. Energy Economics, 41, 90-105. https://doi.org/10.1016/j.eneco.2013.10.019

[7] Zhang, X. and Wang, Y. (2017) How to Reduce Household Carbon Emissions: A Review of Experience and Policy Design Considerations. Energy Policy, 102, 116-124. https://doi.org/10.1016/j.enpol.2016.12.010

[8] Fan, J. and Li, P.X. (2011) Analysis on the Future Energy Consumption and Preliminary Discussion on Carbon Emission of China from the Perspective Urbanization. Advances in Earth Science, 26, 57-65.

[9] Wang, Z. and Yang, L. (2014) Indirect Carbon Emissions in Household Consumption, Evidence from the Urban and Rural Area in China. Journal of Cleaner Production, 78, 94-103. https://doi.org/10.1016/j.jclepro.2014.04.041

[10] Fan, J., Guo, X., Marinova, D., et al. (2012) Embedded Carbon Footprint of Chinese Urban Households, Structure and Changes. Journal of Cleaner Production, 33, 50-59. https://doi.org/10.1016/j.jclepro.2012.05.018

[11] Wang, Z. and Yang, Y. (2016) Features and Influencing Factors of Carbon Emissions Indicators in the Perspective of Residential Consumption, Evidence from Beijing, China. Ecological Indicators, 61, 634-645. https://doi.org/10.1016/j.ecolind.2015.10.015

[12] Rong, P.J., Zhang, L.J., Yang, Q.T., et al. (2016) Spatial Differentiation Patterns of Carbon Emissions from Residential Energy Consumption in Small and $\mathrm{Me}$ dium-Sized Cities, A Case Study of Kaifeng. Geographical Research, 35, 1495-1509.

[13] Ta, N., Shen, Y. and Chai, Y.W. (2016) Progress in Research from a Lifestyle Perspective of Space-Time Behavior. Advances in Earth Science, 35, 1279-1287.

[14] Huang, X.Y., Liu, X.Q. and Cao, X.S. (2015) Commuting Carbon Emission Characteristics of Community Residents of Three Spheres: A Case Study of Three Communities in Guangzhou City. Geographical Research, 34, 751-761.

[15] Lazzerini, G., Lucchetti, S. and Nicese, F.P. (2016) Green House Gases (GHG) Emissions from the Ornamental Plant Nursery Industry, a Life Cycle Assessment (LCA) Approach in a Nursery District in Central Italy. Journal of Cleaner Production, 17, 19-35.

[16] Dale, A.T., Khanna, V., Vidic, R.D., et al. (2013) Process Based Life-Cycle Assessment of Natural Gas from the Marcellus Shale. Environmental Science \& Technology, 47, 59-66. https://doi.org/10.1021/es304414q

[17] Müller, B. and Schebek, L. (2013) Input-Output-Based Life Cycle Inventory. Journal of Industrial Ecology, 17, 504-516. https://doi.org/10.1111/jiec.12018

[18] Hendrickson, C. and Horvath, A. (1998) Economic Input-Output Models for Environmental Life-Cycle Assessment. Environmental Science \& Technology, 32, 184-191. https://doi.org/10.1021/es983471i

[19] Kumar, I., Tyner, W.E. and Sinha, K.C. (2016) Input-Output Life Cycle Environmental Assessment of Greenhouse Gas Emissions from Utility Scale Wind Energy in the United States. Energy Policy, 89, 294-301. https://doi.org/10.1016/j.enpol.2015.12.004

[20] Qin, Y.C., Li, X. and Rong, P.J. (2015) Urban Tourism Carbon Accounting Based on 
Improved EIO-LCA Model, a Case Study of Kaifeng City in Henan Province. Progress in Geography, 34, 132-140.

[21] Heinonen, J. and Junnila, S. (2011) A Carbon Consumption Comparison of Rural and Urban Lifestyles. Sustainability, 3, 1234-1249.

https://doi.org/10.3390/su3081234

[22] Dong, H.J. and Geng, Y. (2012) Study on Carbon Footprint of the Household Consumption in Beijing Based on Input-Output Analysis. Resources Science, 34, 494-501.

[23] Onat, N.C., Kucukvar, M. and Tatari, O. (2014) Scope-Based Carbon Footprint Analysis of U.S. Residential and Commercial Buildings: An Input-Output Hybrid Life Cycle Assessment Approach. Building \& Environment, 72, 53-62. https://doi.org/10.1016/j.buildenv.2013.10.009

[24] Zhang, X., Luo, L. and Skitmore, M. (2015) Household Carbon Emission Research, an Analytical Review of Measurement, Influencing Factors and Mitigation Prospects. Journal of Cleaner Production, 103, 873-883. https://doi.org/10.1016/j.jclepro.2015.04.024

[25] Shi, M.J., Wang, Y., Zhang, Z.Y., et al. (2013) Regional Carbon Footprint and Interregional Transfer of Carbon Emissions in China. Acta Geographica Sinica, 67, 1327-1338.

[26] Perobelli, F.S., Faria, W.R. and Vale, V.D.A. (2015) The Increase in Brazilian Household Income and Its Impact on $\mathrm{CO}_{2}$ Emissions, Evidence for 2003 and 2009 from Input-Output Tables. Energy Economics, 52, 228-239. https://doi.org/10.1016/j.eneco.2015.10.007

[27] Saner, D., Heeren, N., Jaggi, B., et al. (2013) Housing and Mobility Demands of Individual Households and Their Life Cycle Assessment. Environmental Science \& Technology, 47, 5988-5997.

[28] Heinonen, J., Jalas, M., Juntunen, J.K., et al. (2013) Situated Lifestyles, I. How Lifestyles Change along with the Level of Urbanization and What the Greenhouse Gas Implications Are-A Study of Finland. Environmental Research Letters, 8, 1-13. https://doi.org/10.1088/1748-9326/8/2/025003

[29] Heinonen, J., Jalas, M., Juntunen, J.K., et al. (2013) Situated Lifestyles, II. The Impacts of Urban Density, Housing Type and Motorization on the Greenhouse Gas Emissions of the Middle-Income Consumers in Finland. Environmental Research Letters, 8, 1402-1416. https://doi.org/10.1088/1748-9326/8/3/035050

[30] Hendrickson, C., Lave, L. and Matthews, H. (2006) Environmental Life Cycle Assessment of Goods and Services: An Input-Output Approach. Resources for the Future Press, Washington DC.

[31] Han, L. and Xu, X. (2015) Applying Quantile Regression and Shapley Decomposition to Analyzing the Determinants of Household Embedded Carbon Emissions, Evidence from Urban China. Journal of Cleaner Production, 103, 219-230. https://doi.org/10.1016/j.jclepro.2014.08.078

[32] Allinson, D., Irvine, K.N., Edmondson, J.L., et al. (2016) Measurement and Analysis of Household Carbon, the Case of a UK City. Applied Energy, 164, 871-881. https://doi.org/10.1016/j.apenergy.2015.11.054 